Chimia 44 (1990) 361-364

(C) Schweiz. Chemiker-Verband; ISSN 0009-4293

\section{Some Newer Applications of Advanced Polymer Composites}

\author{
Robert F. Siegmund*
}

\section{Introduction}

Advanced polymer composites continue to offer significant opportunity for future industrial growth. One of the most important features is their ability to be tailored to meet specific mechanical and thermal properties. Over the past years, a limiting factor in the use of advanced polymer composites, especially in aerospace applications, has been the reluctance to take complete advantage of their customizing capability. It has been only recently that manufacturers have begun to build composite structures by exploiting the full design benefits of advanced resins and fibers rather than simply using them as a direct substitute for metal. As the composite data base has expanded, yielding increased confidence and reliability, and newer matrices are developed to meet the more demanding performance requirements of primary structural applications, advanced composites are starting to enjoy widespread use. The aerospace industry, where performance, weight, and reduced part count considerations are generally favored over material costs, has led the move. Recent advances in tooling technology and fabrication equipment and expertise has finally begun to lower the traditional high-cost barriers of advanced composite materials and opened up new opportunities in the marine, industrial, and non-aerospace defense markets.

\section{Advanced Polymers}

For purposes of this review, advanced polymer composites include thermoset and thermoplastic resins reinforced with carbon, aramid, or glass fiber. Typical advanced polymer thermoset resins can be classified into four general in-service operating temperature categories (Fig. I). Matrix resins containing phenolic resols or Bis-A-type epoxy resin with an amine hardener (e.g. dicyandiamide), and/or an appropriate modifier and accelerator are normally cured at $121^{\circ}$ and provide use temperatures of up to $80^{\circ}$. The multifunc- tional epoxy and hardener systems are predominately based on tetraglycidyl 4,4'-diaminodiphenylmethane (TGDDM) and 4,4'-diaminodiphenylsulfone (DDS), cure at $177^{\circ}$ and offer continuous service temperatures of $121-135^{\circ}$. The bismaleimide resins exhibit in-service use up to $177^{\circ}$. Finally, polyimides, cured at 285 to $345^{\circ}$, are used primarily in applications that require operating temperatures in excess of $250^{\circ}$, and can retain strength up to $315^{\circ}$.

Advanced composites constructed of high-temperature thermoplastic matrix materials (Fig. 2) have the potential to possess greater toughness, that is, increased resistance to impact damage and strength retention after impact. This feature along with the ease of processing, reworking of scrap material and supportability in the field offer the promise of lower overall costs. Their service-use temperatures vary according to the paticular polymer, but generally the commercially available thermoplastics tend to be evaluated as replacements for $177^{\circ}$ curing epoxies or bismaleimides. In the case of the thermoplastic polyimide Avimid $N$, the applications compete with $P M R$-15 type thermosets. Its service temperature is slightly higher than $P M R-15$ and reportedly can endure shortterm excursions of up to $500^{\circ}$.

\section{Market Potential} vanced polymer composites depends on a variety of factors including cost, performance requirements, and application. Costs can be further divided into raw material, tooling, fabrication, and in-service use. Aerospace, both space and aircraft, generally affords a higher end value for weight reduction and performance than do most industrial, non-aerospace military, and automotive applications (Fig. 3). Recent reductions in defense spending and competitive pressures in the commercial market have made aircraft manufacturers
The current and potential use of ad-

\section{EPOXY}
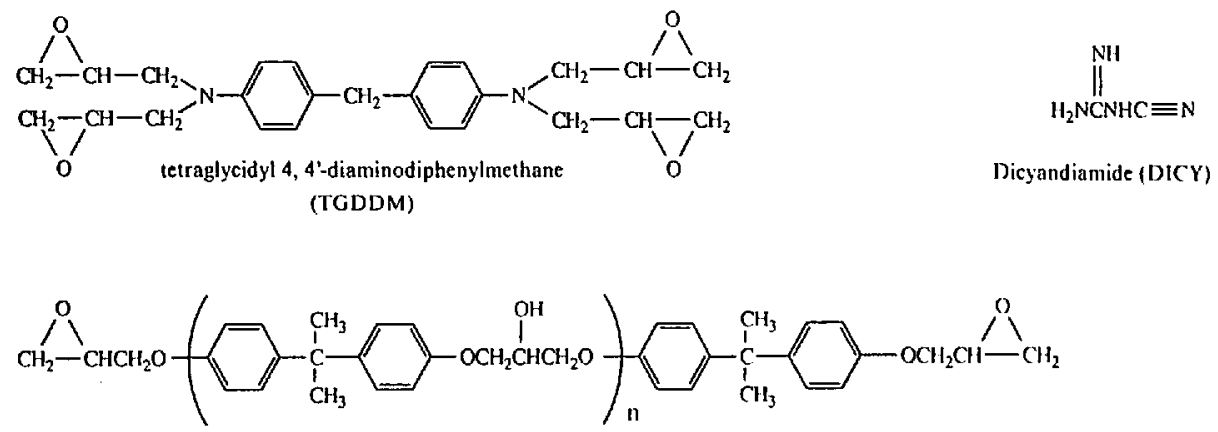

Diglycidyl ether from epichlorohydrin and bisphenol A (DGEBA)

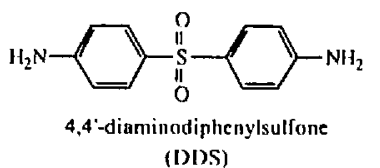

BISMALEIMIDE

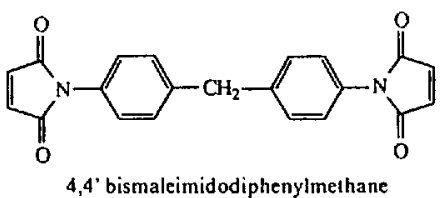<smiles>C=CCc1cc(C(C)(C)c2ccc(O)c(CC=C)c2)ccc1O</smiles>

POLYIMIDE

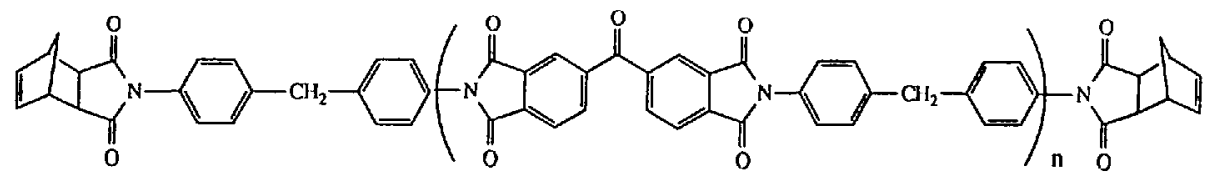

PMR-15

- Correspondence: Dr. R. F. Siegmund Ciba-Geigy Corporation

Fig. 1. Advanced polymer composites. Typical thermoset chemistries. 


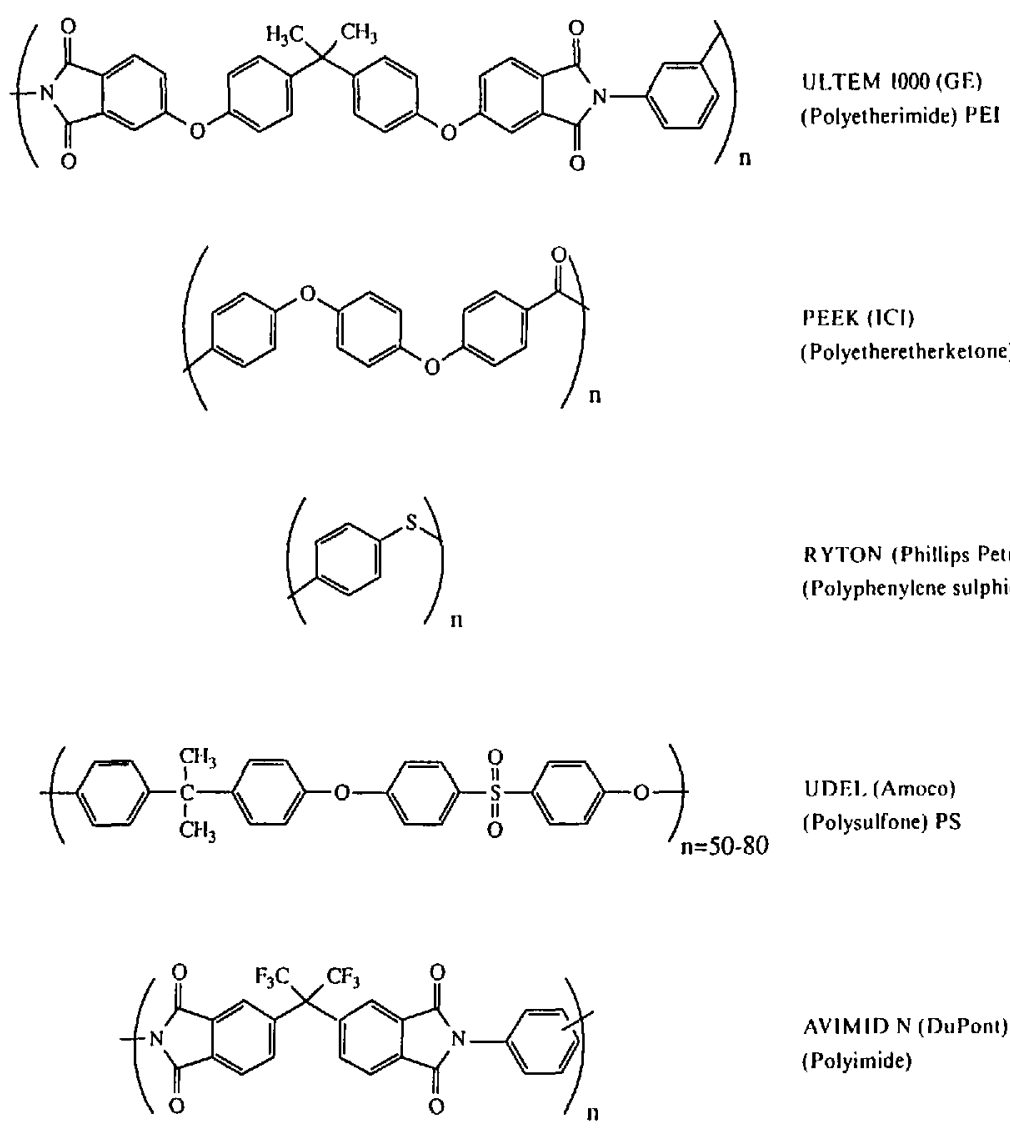

Fig. 2. Advanced polymer composites. Typical thermoplastic chemistries. much more cognizant of overall costs. Presently, fabrication and tooling still represent over $70 \%$ of the total cost of a composite part. Technology advances in these areas are critical to the wide acceptance of advanced polymer composites in the aircraft industry.

During the 1990's, thermosets will continue to dominate high performance composite usage. The advantages of thermoplastics in processability, repair, and longterm service are inhibited by the initial high capital costs associated with replacing the existing thermoset matrix based fabrication equipment. The largest single near- term opportunity for high performance thermoplastics center on development of the United States Air Force Advanced Tactical Fighter (ATF). The long-range cost reduction possibilities, both in acquisition and maintenance, have heavily influenced the Air Force's decision to promote thermoplastics. It is estimated almost $50 \%$ of the proposed aircraft will be composed of composite material. The key question, however, remains whether high-temperature thermoplastic technology necessary to satisfy the ATF performance requirements can be developed in sufficient time to meet the ATF program schedule.

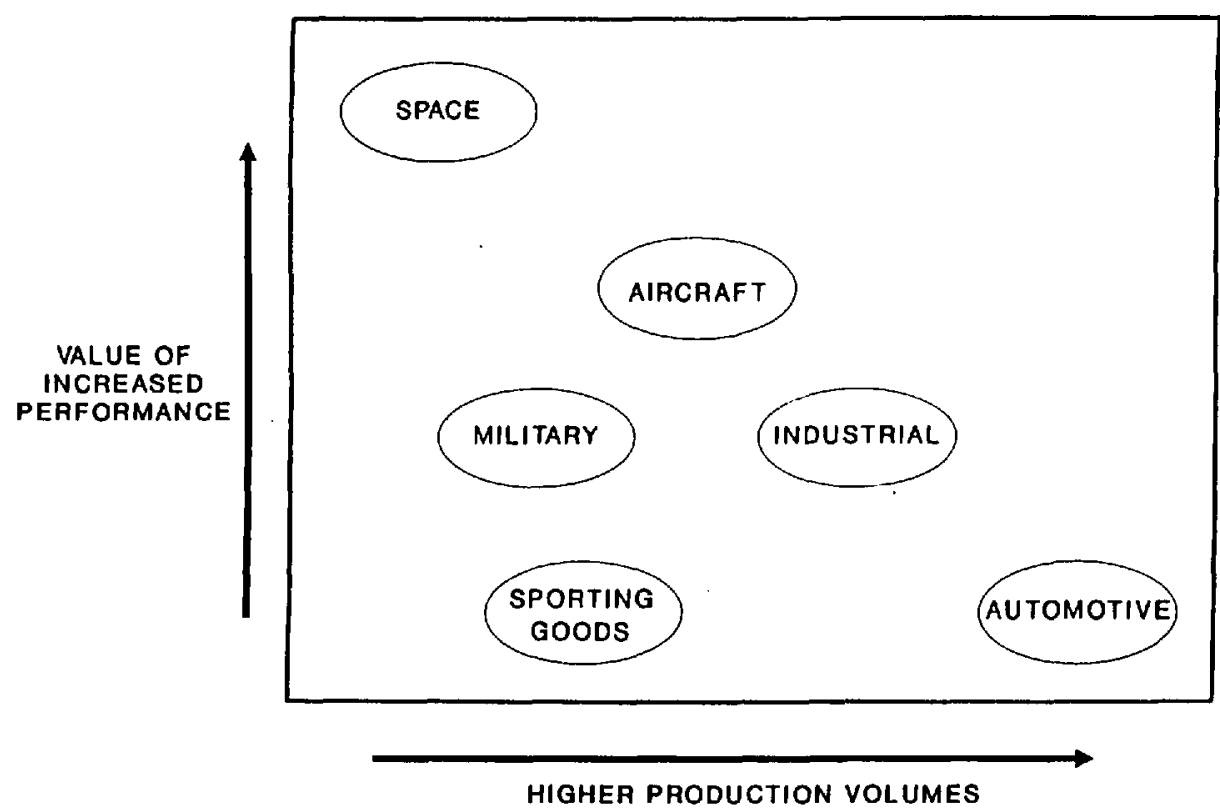

Fig. 3. Potential for advanced polymer composites
Penetration of the industrial and nonaerospace military markets will depend on a reduction in raw material and fabrication costs, and the industry acceptance of new technology. Automotive applications of high performance composites represent the greatest volume opportunity but are the most influenced by cost. Large-scale usage is not anticipated until at least the end of this decade.

From a technology perspective, Fig. 4 summarizes the general direction of new developments in the various market segments. Cost and production rate concerns should ensure advanced polymer composite applications principally reside in aerospace with most other market areas experiencing niche uses where weight or performance factors outweigh the associated high costs and lack of familiarity. A notable exception is the strong regulatory demand for increased fire safety requirements in naval, commercial aircraft, and industrial facilities. This could provide a significant opportunity for composite materials. Low-priced glass or polymeric fiber reinforced with phenolic or thermoplastic resin may achieve the desired flame, smoke, and toxic (FST) properties at an acceptable cost. A second exception could be the aggressive development of industrial, automotive, and sporting goods applications by the Japanese.

\section{Applications}

The development of advanced polymer composites in aerospace began in the mid 1960's. The significant benefits of weight reduction provided the principal thrust. In the 1970's as aramid, boron, and carbon fibers high in specific strength and modulus were introduced, the ability to substitute advanced polymer composites for aluminium in secondary structures became a reality. Over the last twenty years, rapid technology advancements in fibers and matrix resins have resulted in increased aerospace use, initially in secondary structural applications and more recently in primary structures. The substitution of advanced composites for metals can be shown to be an almost direct function of enhancements in fiber tensile strength, modulus, elongation, and matrix resin toughness and hot/wet strength.

Use of advanced polymers in space vehicle applications range from the United States space shuttle (carbon/epoxy and aramid honeycomb for payload bay doors, carbon/epoxy remote manipulator arm, and various use of epoxy and polyimide adhesives) to $\mathrm{C} / \mathrm{C}$ rocket nozzles, carbon/ epoxy filament wound solid rocket motor cases, carbon/polyimide booster tail and fins, and satellite structure and solar panels. Most space applications utilize standard aerospace grade carbon fiber (tensile strength $3550 \mathrm{MPa}$, tensile modulus 235 GPa) combined with a $177^{\circ}$ cure multifunctional epoxy resin matrix. Filament 


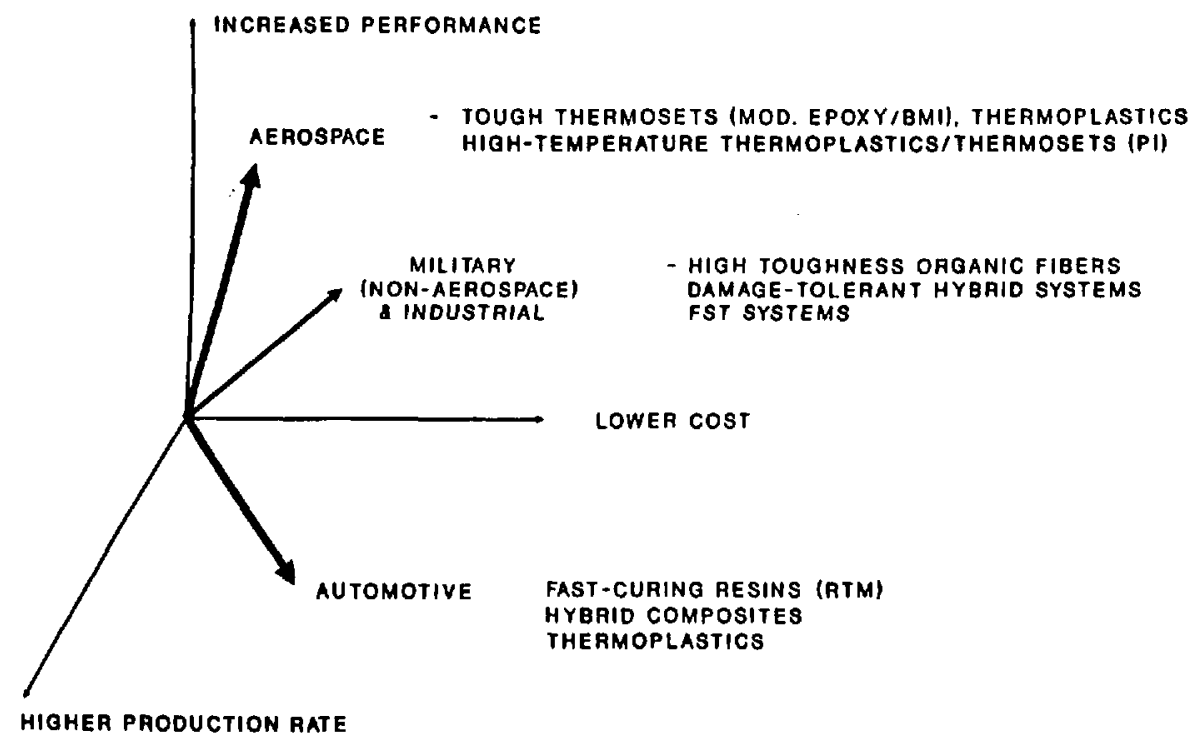

Fig. 4. Development trends for advanced polymer composites

wound rocket motor cases, either $S$-2 glass, aramid or the more typically used standard aerospace grade carbon fiber, generally employ a $121^{\circ}$ cure, modified Bis-A-epoxy as the resin matrix. Stiffness requirements on some satellite applications dictate use of high modulus carbon fiber ( $350 \mathrm{GPa}$ ). Standard strength/modulus carbon fiber and $177^{\circ}$ cure thermoset resin, protected from radiation and atomic oxygen environments by aluminium foil or alternate coating materials, are favored for construction of the proposed composite truss tubes for the U.S. space station.

Aircraft applications of high performance composites have been led by the military industry. In the mid 1970's, one of the first production aircraft to incorporate advanced polymers, Grumman's F-14, contained less than one percent composite. This has steadily increased as new military aircraft were designed and placed into service. The $M c$ Donnell Douglas $A V-8 B$ (mid 1980 's) has over $25 \%$ composite structure, the Suab new generation multi-role $J A S$ - 39 Gripen (late 1980's) has ca. 30\% and the proposed U.S. Air Force ATF is estimated to be comprised of over $50 \%$ advanced polymer composites. Technology improvements in fiber and resin can be found in each new generation of aircraft. The $F-14$ composite structure consisted of a tail skin of $177^{\circ}$ epoxy resin/boron fiber. The $A V$ $8 B$ contains both $177^{\circ}$ cure epoxy and bismaleimide resin with standard aerospace strength/modulus carbon fiber. The most recent produced aircraft (Gripen, EFA, French Rafale, and U.S. B-2) have begun to utilize the $177^{\circ}$ cure toughened thermoset matrix resins along with intermediate modulus (295 GPa), or high strength (5590 MPa), intermediate modulus carbon fiber. The toughened systems have compression-after-impact performance $75 \%$ greater than the base $177^{\circ}$ cure epoxies. As previously noted, the ATF is planned to incorporate thermoplastics or toughened bismaleimide as a primary structural material.
Even in secondary structural applications, newly designed military aircraft have increased quantities of advanced polymers. The U.S.A.F. C-17 transport reportedly contains almost $3000 \mathrm{~kg}$ of composite materials. This does not include advanced polymers used in tooling and fabrication. The wing to body fairing production tooling package alone contains over $8500 \mathrm{~m}^{2}$ of $177^{\circ}$ epoxy/carbon prepreg and tooling material. Advanced composites are also employed to retrofit older military aircraft. The Grumman A-6 fighter is currently being modified with epoxy/carbon composite wings.

Helicopter airframe builders have long been in the forefront of utilizing composites in both military and commercial craft. The all composite $M B B B K 117$ helicopter is $c a$. two-thirds carbon fiber/epoxy. As is typical in helicopters, both $121^{\circ}$ and $177^{\circ}$ systems are used. Aramid and glass/epoxy comprise the remaining one-third. Bell Boeing's revolutionary $V-22$ Osprey, with its all composite fuselage, contains multiple innovative uses of advanced polymer composites. Depending on the specific application, carbon, glass, or aramid fibers are employed. Intermediate modulus carbon fiber and $177^{\circ}$ epoxy are found in areas such as the wing assemblies that require high stiffness.

With safety, cost, and long-term reliability considerations regarded as critical parameters, commercial aircraft manufactures have made the transition from metals to advanced polymers more slowly than their military counterparts. However, the continual development of a composite performance data base, and fiber and toughened resin advancements have permitted a steadily increasing use of composites. From the Beech Starship to the Boeing 777 and Airbus A330/A340 development programs, aircraft designs are beginning to employ advanced polymers in primary as well as secondary strutures. The Airbus A310/A320 vertical tail fin boxes $\left(121^{\circ}\right.$ cure toughened epoxy/carbon fiber), the $A 320$ horizontal tail fin $\left(177^{\circ}\right.$ cure epoxy/carbon), and the $A T R 72$ external wing box $\left(177^{\circ}\right.$ toughened epoxy/carbon) represent three major primary structural applications. Proposed large-scale commercial airframe structures include the Airbus $A 330 / A 340$ composite fuselage, and structural wing and tail components (Airbus and Boeing). The proposed Boeing 777 tail assembly will reportedly employ the recently developed $177^{\circ}$ cure 'second generation' toughened thermosets. These materials can provide compression-after-impact, values $150 \%$ above the standard TGDDM/DDS systems. For future aircraft, the U.S. space agency, NASA, has multiple on-going programs to develop advanced polymer composites for commercial applications. The "High Speed Commercial Transport' program is evaluating bismalcimide and thermoplastic materials for use at service temperatures of $177^{\circ}$ and higher. In another NASA effort, 'Advanced Composite Technology', three dimensional stitched reinforcements, injection molded with low-flow $177^{\circ}$ cure thermosets, are being considered as alternates to highly toughened matrix systems.

Commercial aircraft engine use of advanced polymers in both new and retrofit applications are numerous. Weight reduction is the primary advantage. The wide service temperature profile of a jet engine results in a range of advanced polymer matrices being used to meet the varying temperature requirements. Outer and front sections of the engine are subjected to lower temperatures and can utilize epoxy/ carbon. The front fan ducts on Rolls Rovee engines and the blocker doors and transcowls on General Electric's CF6-80C2 engines are examples of components fabricated with $177^{\circ}$ epoxy/carbon fiber. The G.E. engine also has an aramid blade containment ring to protect the fan in the event of blade breakage. Aramid honeycomb, epoxy/carbon 'hush kits' designed to facilitate noise abatement on older engines offer an inexpensive alternative to retrofitting aircraft with new engines.

Engine rear section components operate at higher temperatures which necessitate polyimide-type resin matrices. PMR-15/ carbon are currently used in a number of engine applications including thrust reversers and bypass ducts. Thermoplastics, PEEK and PAS in lower temperature areas, and Aramid N, for higher temperature use, are under investigation by several engine manufacturers for potential composite applications.

Industrial applications have centered on performance enhancement and weight reduction. State-of-the-art advanced polymer technology has been applied to automotive, sports competition boats and commercial marine craft.

A rapidly emerging area for advanced composites exists in the development of systems designed to meet the new fire and toxicity regulatory guidelines for aircraft interiors, marine surface-ships, and com- 
mercial buildings. The market growth prospects are significant, since not only newconstruction but also the upgrade of existing systems are involved. Advanced low FST composite materials for aircraft, principally based on phenolic or thermoplastic resins, that reportedly conform to the proposed FAA 1990 rule and the Airbus Industries ATS 1000.001 specification have been introduced by a number of companies. Composite suppliers are also quite active in the development of FST aircraft floor panels. Hexcel and Quadrax have teamed to produce a thermoplastic sand. wich panel to fulfill this requirement.

Although the most widely known firesuppression programs are directed at aircraft interiors, potential applications include most areas in marine surface ships above the water line (e.g. deck houses, joiner panels, ducts, and armor), aircraft engine cowlings, and burn through barriers in air conditioning ducts, elevator shafts, office partitions, hospital walls, utility control rooms, and emergency shelters. The United States Navy has several development programs evaluating the applicability of advanced composites on surface-ships and submarines. Weight reduction and fire properties are the main parameters of interest. An example of a commercial realization of the composite industry's $R \& D$ efforts is a new lightweight low FST composite system recently offered by $\mathrm{Ciba}$ Geigy. The material is manufactured as a sandwich structure and capable of O.S.U. values of $10 / 10$. It meets the toxicity requirements of ATS 100 and U.S. domestic specifications. Utilizing specific constructions, it can provide $1-h$ burn through protection in a $1093^{\circ}\left(2000^{\circ} \mathrm{F}\right)$ direct flame. Large-scale component tests have been successfully conducted in several U.S. Navy ship applications including fire main pipes and air conditioning ducts.

\section{Conclusion}

Advanced polymer composites have been successfully used in a wide variety of commercial applications. Carbon, glass, and organic fibers combined with thermoset and/or thermoplastic matrix resins have provided performance, weight, and cost advantages over traditional materials. Future use will be influenced by advanced polymer technology advancements and reductions in fabrication and tooling costs.

The author would like to express his appreciation to Richard Heitkamp and Tom Jonas, Ciha-Gieigy. Composite Products, Anahcim, California, for their technical assistance in preparing this papcr.

[1] C.A. May, Ed., 'Resins for Aerospace', ACS Symposium Series, No.132, American Chemical Society, Washington, DC, 1980

[2] G. Pritchard, Ed., 'Developments in Reinforced Plastics-1', Resin Matrix Aspects. Applied Science Publishers L.td.. London, 1980.

\title{
A Study on the Toughening of Polymer Matrix Composites by Interphase Modification
}

\author{
Andrea Pavan*
}

\section{Introduction}

While the combination of different materials to produce a composite with new or enhanced properties is an established concept, the interaction of the constituent phases along their interfaces remains of some concern.

It is generally assumed that a certain degree of adhesion between matrix and inclusion is necessary to provide some degree of collaboration; but it has also been demonstrated that too strong an interfacial bond may impair some properties of the overall composite material, especially toughness. For optimum performance, the magnitude of the interfacial bond strength should be adjusted for each specific application [1].

Modification of the interface by surface treatment (of the inclusions) to adjust the interfacial bond must take into consideration surface morphology and energetics.

\section{Interfaces and Interphases}

In discussing the interfaces between different composite constituents, the fact must not be ignored that the actual contact surface is not a geometrically clear-cut surface, nor are the properties of the two components close to the interface the same as they are in the bulk: all solid phases have skins, whose characteristics are determined by the conditions prevailing at the boundary between the phases in the course of composite preparation and processing.

Conceptually, we are brought to consider the existence of interphase regions of some finite thickness, with variable composition and microstructure. The properties and extent of these regions can have pronounced influence on the properties of the composite material, especially in terms of mechanical strength and chemical and thermal durability.
Having recognized this fact, considerable research effort has lately been devoted, on the one hand, to exploit the possibilities of altering the composition and structure of the interphase, so as to improve composite performance, and, on the other, to characterize and understand the effect of the interphases on the overall properties of the composite material. It is believed that, if accurate predictive models of interphase behaviour can be developed and integrated into a model of composite performance, it may be possible to consider the interphase a composite variable that can itself be varied in a rational manner to optimize composite performance [2].

From Interphases to Interlayers: Some Recent Experimental Achievements

Since control of the interphases, which form spontaneously, in situ, during composite preparation, may be a rather difficult task, an obvious alternative is the introduction of relatively thick interlayers, encapsulating the particulate or fibrous inclusions. It is felt that the structure, properties, and thickness of a relatively thick third phase can be more easily predetermined and tailor-made.

\footnotetext{
* Correspondence: Prof. Dr. A. Pavan Dipartimento di Chimica Industriale e Ingegneria Chimica Politecnico di Milano Piazza Leonardo da Vinci 32 I-20133 Milano
} 